KONSTAN
JURNAL FISIKA DAN PENDIDIKAN FISIKA
Volume 3, Nomor 2, Desember 2018
$\begin{array}{r}\text { E-ISSN : 2460-9129 dan P-ISSN : 2460-9110 } \\ \text { http://jurnalkonstan.ac.id/index.php/jurnal }\end{array}$

\title{
PEMETAAN AKUIFER DI DAERAH BIMA UNTUK INVENTARISASI DALAM PENGELOLAAN SUMBER DAYA AIR TANAH SECARA BERKELANJUTAN
}

\author{
Arif Rahman Hakim ${ }^{1 *}$, Hairunisa ${ }^{2}$ \\ ${ }^{1,2}$ STKIP Taman Siswa Bima, Jl. Pendidkan Taman Siswa No. 1 Palibelo, Bima, Nusa \\ Tenggara Barat, Indonesia
}

\section{Info Artikel}

Sejarah Artikel:

Diterima Oktober 2018

Disetujui Oktober 2018

Dipublikasikan Desember

2018

\section{Kata Kunci:}

Pemetaan Akuifer, Pengelolaan Sumber Daya

Air, Geolistrik,

Schlumberger

\begin{abstract}
Abstrak
Penelitian ini bertujuan untuk memetakan potensi dan sebaran akuifer di Desa Rada Kecamatan Bolo Kabupaten Bima sebagai langkah awal dalam pengelolaan sumberdaya pasir secara berkelanjutan. Penelitian ini dilakukan dengan menggunakan metode geolistrik resistivitas konfigurasi schlumberger dimana pengukurannya dilakukan pada 10 titik dengan panjang bentangan 400 meter dan masing-masing titik berjarak 50 meter. Data primer yang dibutuhkan dalam penelitian ini adalah besar arus yang diinjeksikan $(I)$, beda potensial yang terjadi $(\Delta V)$ dan Nilai hambatan $(R)$. Hasil penelitian menunjukkan bahwa lapisan akuifer di daerah penelitian berada pada kedalaman 16 meter sampai 100.6 meter dengan ketebalan yang bervariasi, yaitu antara 4.2 meter sampai 62.2 meter dengan nilai resistivitas berkisar antara $6 \Omega \mathrm{m}$ sampai $106 \Omega \mathrm{m}$. Selain itu, terdapat dua sebaran akuifer yakni sebaran akuifer pertama terdapat pada titik pengukuran RD01, RD02, RD03, RD08, RD09, RD10 dan sebaran akuifer kedua pada titik pengukuran RD04, RD05, RD06, RD07. Dari hasil penelitian juga, diperkirakan titik yang dianggap paling berpotensi untuk kegiatan eksplorasi air tanah yaitu pada titik RD01 dengan perkiraan kedalaman $25.4 \mathrm{~m}$ dan ketebalan $62 \mathrm{~m}$ dan titik RD10 dengan perkiraan kedalaman 17.6 meter dan ketebalan 26 meter. Kedua titik tersebut mempunyai ketebalan lebih dari 25 meter sehingga diperkirakan mempunyai volume air yang besar dibanding dengan titik yang lain.
\end{abstract}

(C) 2018 Universitas Islam Negeri Mataram
Alamat korespodensi:

Gedung Pasca Sarjana Lantai 3 Kampus 2 UIN Mataram, Jl. Gajah Mada 100 Jempong Mataram, Indonesia Email: jurnalkonstan@uinmataram.ac.id 


\section{PENDAHULUAN}

Air merupakan salah satu sumber energi utama yang digunakan oleh makhluk hidup dalam proses kehidupannya. Air yang digunakan adalah berasal dari air tanah dan air bawah tanah. Ait tanah merupakan air yang letaknya berada di permukaan tanah (misal: sungai, danau, dll), sedangkan air bawah tanah merupakan air yang letaknya berada di bawah permukaan tanah (misal: sungai bawah tanah, air sumur, dll) [1]. Air pada umumnya meresap ke dalam tanah melalui dua sistem, yakni sistem air jenuh dan sistem air tidak jenuh. Sistem air jenuh merupakan air bawah tanah yang terletak pada suatu lapisan batuan dan berada pada suatu cekungan pasir. Air ini biasanya dapat tersimpan dan mengalir pada lapisan batuan yang dikenal dengan akuifer (aquifer). Akuifer merupakan suatu lapisan batuan jenuh pasir yang dapat menyimpan dan meneruskan pasir dalam jumlah cukup [2].

Seiring dengan pertumbuhan penduduk dan perkembangan peradaban manusia, kebutuhan air sebagai kebutuhan primer semakin meningkat dari tahun ke tahun dan menjadi masalah, baik untuk kebutuhan sehari-hari, pertanian dan perternakan. Kondisi ini terjadi di beberapa daerah di Kabupaten Bima salah satunya adalah Desa Rada Kecamatan Bolo. Dimana debit air dari sumber mata air dan sungai sudah tidak dapat memenuhi kebutuhan air masyarakat setempat. Hal ini terjadi karena kondisi daerah resapan air di daerah tersebut sebagian besarnya telah digunakan sebagai daerah pemukiman.

Kondisi air tanah yang demikian menjadikan masyarakat di Desa Rada hanya mengandalkan tampungan air hujan dan sumber air yang sedikit jauh dari pemukiman dengan debit air yang sangat kecil terutama pada musim kemarau. Karena intensitas hujan yang rendah dan musim basah yang pendek, menjadikan daerah ini kering. Pada saat musim kemarau, daerah ini berpotensi mengalami kekurangan air, begitu juga sebaliknya pada saat musim hujan daerah ini berpotensi terkena banjir.

Untuk memecahkan masalah tersebut, maka perlu dilakukan pemetaan sebaran potensi cekungan air tanah (akuifer) bawah permukaan. Pemetaan potensi akuifer ini dapat dilakukan dengan menggunakan metode geolistrik resistivitas. Metode ini sangat terkenal dalam mendeteksi kualitas air tanah dan lapisan akuifer bawah permukaan dan telah terbukti banyak memecahkan masalah mengenai air tanah. Hal ini telah dibuktikan dengan hasil penelitian yang telah dilakukan oleh Dinisa Hanifa pada Tahun 2016 dengan Judul "Penentuan Lapisan Akuifer Air Tanah Dengan Menggunakan Metode Geolistrik Resistivitas Konfigurasi Schlumberger Di Desa Sungai Jati Kecamatan Mataraman Kabupaten Banjar Kalimantan Selatan". Hasil penelitian tersebut menyatakan bahwa dari 6 titik penelitian menunjukkan bahwa akuifer berada pada kedalaman 6 meter sampai 40 meter dan ketebalan berkisar antara 2 sampai 11 meter dengan nilai resistivitas 100 sampai 450 Ohm meter [3].

Prinsip dasar metode ini adalah dengan memanfaatkan kemampuan hantaran listrik batuan bawah permukaan dan sifat geologinya. Dimana arus listrik diinjeksikan melalui suatu elektroda sehingga diperoleh nilai beda potensial dari lapisan tanah bawah permukaan daerah yang diukur. Hasil akhir dari metode geolistrik resistivitas ini adalah nilai resistivitas bawah permukaan. Nilai 
resistivitas ini dapat digunakan untuk menduga atau memprediksi jenis lapisan tanah dan akuifer. Pendugaan ini diharapkan dapat membantu masyarakat setempat untuk menentukan daerah eksplorasi air yang tepat.

\section{METODE PENELITIAN}

Penelitian ini merupakan pengembangan dari penelitian yang telah dilakukan Arif rahman hakim dan Hairunisa pada tahun 2018 dengan judul "Survey Geofisika Metode Geolistrik Resistivitas Untuk Menentukan Struktur Bawah Permukaan Desa Rada Kecamatan Bolo Kabupaten Bima". Penelitian ini dilakukan dengan mengolah data sekunder yang diperoleh dari hasil penelitian sebelumnya. Menurut [4], penelitian ini menggunakan metode geolistrik resistivitas konfigurasi schlumberger. Prinsip dari metode ini adalah dengan menginjeksikan arus listrik ke dalam permukaan tanah melalui dua buah elektroda arus A dan B sehingga terekam nilai beda potensial listrik yang terukur melalui dua buah elektroda potensial $\mathrm{M}$ dan N. Data yang diperoleh dari pengukuran ini berupa kuat arus $(I)$, beda potensial $(V)$ dan jarak spasi antar elektroda $(a)$.

Ada 3 tahap penting yang perlu dilakukan dalam penelitian ini, antara lain :

\section{Akuisisi Data}

Langkah awal yang dilakukan salah satunya adalah orientasi lapangan dan pengamatan kondisi geologi. Panduan ini dijadikan informasi dan sebagai bahan pertimbangan dalam menentukan langkah selanjutnya, yaitu perencanaan lokasi lintasan dan pengambilan data yang meliputi perancanaan lokasi penelitian, posisi titik (sounding), jarak spasi titik dan panjang lintasan. Selain itu, perlu adanya informasi mengenai daerah yang akan dilakukan studi, apakah daerah tersebut bermasalah atau tidak (misal sengketa tanah).

Sebagai input, arus DC diinjeksikan ke tanah (orde arus adalah 2 sampai 100 mili ampere), melalui elektrode luar $(A B)$. Selanjutnya, akan didapatkan tegangan terukur yaitu keluaran dari elektrode dalam $(\mathrm{AB})$ berupa beda potensial $(\Delta V)$, arus listrik $(I)$ dan hambatan $(R)$. Jarak untuk masing-masing elektrode juga dicatat yaitu $A B / 2$ dan $M N$ [5].

Proses pengambilan data (akusisi) dilakukan dengan konfigurasi Schlumberger dengan panjang bentangan $\mathrm{AB}$ antara 400 meter. Jumlah titik sounding 10 titik, masing-masing titik berjarak 50 meter yang membentuk grid persegi. Prosedur sounding untuk konfigurasi Schlumberger sebagai berikut :

a. Tempatkan elektroda-elektroda arus $A B$ dan tegangan $M N$ dengan konfigurasi Schlumberger pada bentangan terpendek yang direncanakan. Catat kuat arus listrik dan nilai resistan yang terukur.

b. Pindah elektroda arus $A B$ (elektroda potensial $M N$ tetap) pada jarak ke 2 yang telah ditentukan. Catat kuat arus listrik dan nilai hambatan yang terukur. Arah bentangan antara $A, N, M$ dan $B$ harus lurus.

c. Lakukan langkah pada poin b (dapat berkali-kali ) sampai pembacaan nilai resistannya sangat kecil. Biasanya perpindahan elektroda arus $\mathrm{AB}$ (elektroda potensial $M N$ tetap) dapat ditentukan sampai beberapa kali tergantung kemampuan alat ukurnya. 
d. Jika nilai resistan menunjukkan nilai yang sangat kecil pindahkan elektroda tegangan $M N$ pada posisi 2 yang sudah ditetapkan dengan elektroda arus $A B$ tetap.

e. Apabila poin d tidak ada masalah, maka lakukan langkah b-d sampai dengan jarak bentangan maksimum yang direncanakan.

Data yang diambil dari penelitian ini meliputi data primer, yaitu: Jarak antar elektroda (jarak elektroda $A B$ dan $M N$ ), Jarak antar titik sounding, Besar arus yang diinjeksikan $(I)$, Beda potensial yang terjadi $(\Delta V)$ dan Nilai hambatan $(R)$ [6].

\section{Pengolahan Data}

Metode geolistrik resistivitas konfigurasi Schlumberger merupakan salah satu konfigurasi elektroda dalam survey geolistrik resistivitas yang menampilkan hasil analisa dalam bentuk penampang lintasan bawah permukaan tanah. Penampang yang dihasilkan adalah hubungan antara nilai resistivitas dengan kedalaman pendugaan.

Data yang diperoleh dari daerah penelitian diolah menggunakan software Excel, IPI2WIN dan PROGRESS3. Pada software Excel digunakan untuk mengolah data posisi yang meliputi koordinat posisi dan perhitungan resistivitas $(\rho)$ berdasar nilai arus $(I)$ dengan satuan Ampere, nilai beda potensial $(\Delta V)$ dengan satuan Volt, nilai hambatan $(R)$ dengan satuan Ohm dan jarak bentangan $(M N$ dan $A B / 2$ ) dengan satuan Meter. Nilai resistivitas didapat dengan mengalikan nilai resistansi $(R)$ yang didapat dengan faktor konfigurasi $(K)$. Selanjutnya nilai resistivitas ini digunakan sebagai input pada software IPI2WIN [7].

Software IPI2WIN dan PROGRESS3 berguna untuk menentukan nilai resistivity sebenarnya. IPI2WIN merupakan program komputer yang didesain secara otomatis menjelaskan model resisivitas satu dan dua dimensi di bawah permukaan tanah secara vertikal. Input data pada software IPI2WIN antara lain, jarak bentangan $(A B / 2$ dan $M N)$ dan nilai resistivitas yang sebelumnya sudah dihitung pada sotfware Excel. Proses selanjutnya dilakukan inversi. Hasil yang didapat berupa tampilan grafik dan nilai resistivitas batuan sebenarnya. Untuk mempermudah pembacaan resistivitas satu dimensi digunakan software PROGRESS3, yaitu dengan memasukkan nilai hasil inversi IPI2WIN [8].

Dalam software PROGRESS3 dapat menampilkan hasil resistivity secara log yaitu hubungan kedalaman dengan nilai resistivitas, sehingga memudahkan dalam interpretasi. Variabel masukan pertama kali menggunakan forward modeling kemudian inverse modeling sehingga diperoleh nilai kesalahan minimum berupa nilai RMS (Root Mean Square) minimum dengan parameter yang berupa lapisan, kedalaman dan nilai resistivitas semu $\left(\rho_{\mathrm{a}}\right)$. Selanjutnya akan dilakukan interpretasi data sebagai hasil pengolahan yang berupa kurva nilai resistivitas yang sebenarnya $(\rho)$, ketebalan tiap lapisan dan kedalaman lapisan [9].

Pemodelan 2D dapat dilakukan dengan cara manual, yaitu dengan menghubungkan lapisan-lapisan antar titik studi. Hal ini ditandai dengan nilai resistivitas yang hampir sama. Nilai resistivitas menunjukkan jenis lapisan tanah sehingga pada model 2D terlihat lapisan-lapisan batuan penyusun dari permukaan tanah sampai kedalaman tertentu. Masing-masing lapisan batuan penyusun ditandai dengan warna yang berbeda sesuai nilai resistivitasnya [10]. 
Untuk menentukan pola sebaran akuifer dari semua titik pengukuran diperlukan adanya pemodelan secara tiga dimensi (3D) yaitu dengan menggunakan software SURFER8. Dari interpretasi masing-masing titik pengukuran dibuat model tiga dimensinya dengan menghubungkan posisi koordinat $\mathrm{X}, \mathrm{Y}$ yang sebelumnya telah diinput pada software Excel dan $\mathrm{Z}$ sebagai nilai resistivitas pada kedalaman tertentu [11]. Pada studi ini diambil tiap kedalaman 10 meter.

\section{Interpretasi Data}

Interpretasi data merupakan langkah akhir penelitian yang dilakukan. Pada tahap ini, hasil pengolahan data diartikan untuk mengetahui gambaran kondisi bawah permukaan daerah yang diteliti. Interpretasi dilakukan berdasarkan hasil penampang 2 dimensi dan akan dikorelasikan dengan data tabel nilai resistivitas serta peta geologi daerah penelitian [12].

Pada dasarnya data mentah yang diperoleh pada saat akuisisi berupa data arus (I) dan hambatan (R). Kemudian kedua data tersebut diinput ke dalam Microsoft excel untuk dihitung nilai beda potensialnya (V). Perhitungan beda potensial ini mengacu pada rumus dasar prinsip hukum Ohm [13], yakni:

$$
R=\frac{\Delta V}{I}
$$

Hasil yang akan diperoleh dari olahan data tersebut berupa nilai resistivitas semu. Untuk mendapatkan nilai resistivitas sebenarnya maka digunakan bantuan software IPI2WIN dan PROGRESS3. Hasil inversi berupa gambar model penampang resistivitas daerah penelitian yang menggambarkan distribusi resistivitas bawah permukaan tanah yang menunjukkan keberadaan akuifer [14].

\section{HASIL DAN PEMBAHASAN}

\section{A. Hasil Penelitian}

Berdasarkan hasil penelitian yang telah dilakukan oleh Arif Rahman Hakim dan Hairunisa tahun 2018, mengatakan bahwa Desa Rada Kecamatan Bolo Kabupaten Bima tersusun atas beberapa lapisan, antara lain: top soil yang berupa campuran pasir dan kerikil yang mengalami pelapukan, lava, andesit, dan pasir [4].

Penelitian ini lebih fokus pada pemetaan dan sebaran akuifer dalam mengelola sumber daya air tanah. Keberadaan air tanah (akuifer) bawah permukaan dapat diduga berdasarkan nilai resistivitas batuan penyusunnya, yaitu ditandai dengan adanya lapisan batuan pasir. Batu pasir memiliki porositas dan permeabbilitas yang tinggi sehingga diduga dapat menyimpan air tanah dalam jumlah yang cukup banyak.

Berdasarkan hasil pengolahan data, lapisan akuifer di daerah penelitian hampir terdapat di setiap titik pengukuran dengan kisaran nilai resistivitas yang bervariasi yaitu berkisar antara $6 \Omega \mathrm{m}$ sampai $106 \Omega \mathrm{m}$ seperti yang ditunjukkan pada Tabel 1. 
Tabel 1. Interpretasi Data Geolistrik

\begin{tabular}{|c|c|c|c|c|}
\hline Titik & $\begin{array}{c}\text { Resistivitas } \\
(\Omega \mathrm{m}) \\
\end{array}$ & $\begin{array}{c}\text { Ketebalam } \\
(\mathbf{m})\end{array}$ & $\begin{array}{c}\text { Kedalaman } \\
(\mathbf{m})\end{array}$ & $\begin{array}{r}\text { Pendugaan } \\
\text { Litologi } \\
\end{array}$ \\
\hline \multirow[t]{7}{*}{ RD01 } & 1189 & 5.6 & $0-5.6$ & Top Soil \\
\hline & 805 & 4.2 & $5.6-9.8$ & Lava \\
\hline & 118 & 8.1 & $9.8-17.9$ & Andesit \\
\hline & 1320 & 7.5 & $17.9-25.4$ & Lava \\
\hline & $6.3-93$ & 62.2 & $25.4-87.6$ & Pasir \\
\hline & $159-270$ & 41.4 & $87.6-129$ & Andesit \\
\hline & 450 & $\begin{array}{c}\text { Tak } \\
\text { terhingga }\end{array}$ & $129-\sim$ & Lava \\
\hline \multicolumn{5}{|l|}{ RD02 } \\
\hline & $220-290$ & 16 & $0-16$ & Top soil \\
\hline & 63 & 12.5 & $16-28.5$ & Pasir \\
\hline & $895->1000$ & 28.5 & $122-\sim$ & Lava \\
\hline \multirow[t]{4}{*}{ RD03 } & 672 & 5.3 & $0-5.3$ & Top soil \\
\hline & 138 & 19.6 & $5.3-25$ & Andesit \\
\hline & $15-87$ & 5.6 & $35.4-41$ & Pasir \\
\hline & $385->1000$ & $\begin{array}{c}\text { Tak } \\
\text { terhingga }\end{array}$ & $41-\sim$ & Lava \\
\hline \multirow[t]{2}{*}{ RD04 } & $722->1000$ & 8.6 & $0-8.6$ & Top soil \\
\hline & $163->1000$ & $\begin{array}{c}\text { Tak } \\
\text { terhingga }\end{array}$ & $8.6-\sim$ & Andesit \\
\hline \multirow[t]{6}{*}{ RD05 } & $556->1000$ & 17 & $0-17$ & Top soil \\
\hline & 112 & 14.9 & $17-31.9$ & Andesit \\
\hline & $66-93$ & 12.5 & $31.9-44.4$ & Pasir \\
\hline & 257 & 12 & $44.4-56.4$ & Andesit \\
\hline & $375-768$ & 27.1 & $56.4-83.5$ & Lava \\
\hline & $74-98$ & $\begin{array}{c}\text { Tak } \\
\text { terhingga }\end{array}$ & $96.5-\sim$ & Pasir \\
\hline \multirow[t]{5}{*}{ RD06 } & $456-762$ & 20 & $0-20$ & Top soil \\
\hline & 27.5 & 13 & $20-33$ & Pasir \\
\hline & 195 & 12 & $33-34.2$ & Andesit \\
\hline & $297-569$ & 40 & $34.2-74.2$ & Lava \\
\hline & $15-100$ & $\begin{array}{c}\text { Tak } \\
\text { terhingga }\end{array}$ & $74.2-\sim$ & Pasir \\
\hline \multirow[t]{5}{*}{ RD07 } & $727->1000$ & 17 & $0-17$ & Top soil \\
\hline & 145 & 10.8 & $17-27.8$ & Andesit \\
\hline & $>1000$ & 62.7 & $27.8-90.5$ & Lava \\
\hline & 11.6 & 10.1 & $90.5-100.6$ & Pasir \\
\hline & $725->1000$ & $\begin{array}{c}\text { Tak } \\
\text { terhingga }\end{array}$ & $100.6-\sim$ & Lava \\
\hline RD08 & 434 & 8.5 & $0-8.5$ & Top soil \\
\hline
\end{tabular}




\begin{tabular}{ccccc}
\hline & 173 & 9 & $8.5-17.5$ & Andesit \\
\cline { 2 - 5 } & 24 & 6.2 & $17.5-23.7$ & Pasir \\
\cline { 2 - 5 } & $196->1000$ & $\begin{array}{c}\text { Tak } \\
\text { terhingga }\end{array}$ & $23.7-\sim$ & Lava \\
\hline RD09 & $277-927$ & 18 & $0-18$ & Top soil \\
\cline { 2 - 5 } & 44 & 9 & $18-27$ & Pasir \\
\cline { 2 - 5 } & $476->1000$ & $\begin{array}{c}\text { Tak } \\
\text { terhingga }\end{array}$ & $27-\sim$ & Lava \\
\hline RD10 & $264-907$ & 17.6 & $0-17.6$ & Top soil \\
\cline { 2 - 5 } & 65 & 4.2 & $17.6-21.8$ & Pasir \\
\cline { 2 - 5 } & 1122 & 5.2 & $21.8-27$ & Lava \\
\cline { 2 - 5 } & 246 & 22.8 & $27-49.8$ & Andesit \\
\cline { 2 - 5 } & $27-106$ & 26.2 & $49.8-76$ & Pasir \\
\cline { 2 - 5 } & $143-194$ & $\begin{array}{c}\text { Tak } \\
\text { terhingga }\end{array}$ & $76-\sim$ & Andesit \\
\hline
\end{tabular}

\section{: Lapisan akuifer}

Dari data pada Tabel 1 di atas, kemudian dilakukan pemodelan 2D sehingga diketahui potensi keberadaan dan kedalaman lapisan akuifer berdasarkan nilai resistivitasnya. Potensi keberadaan lapisan akuifer di daerah penelitian hampir terdapat pada setiap titik pengukuran dengan kedalaman dan ketebalan yang berbeda. Keberadaan dan kedalaman lapisan akuifer daerah penelitian dapat ditunjukkan oleh Gambar 1 dan Gambar 2.

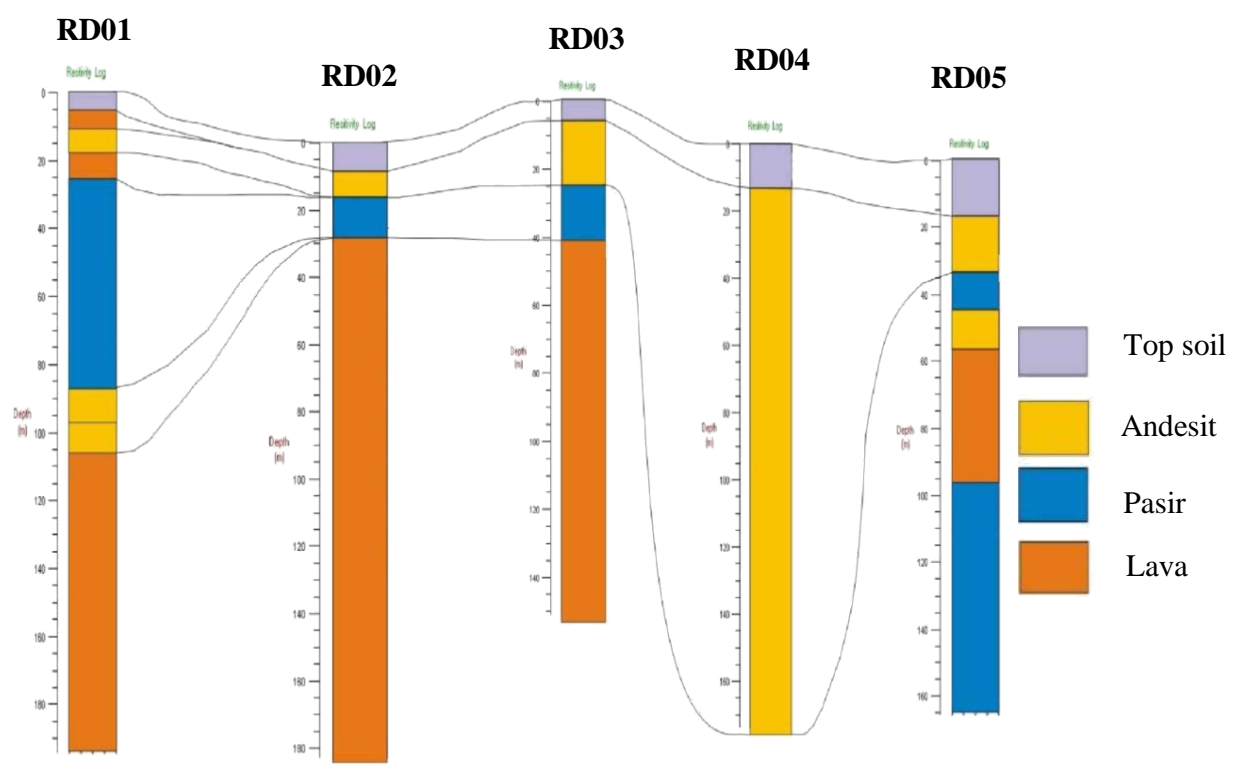

Gambar 1. Penampang 2D Titik RD01 sampai RD05 


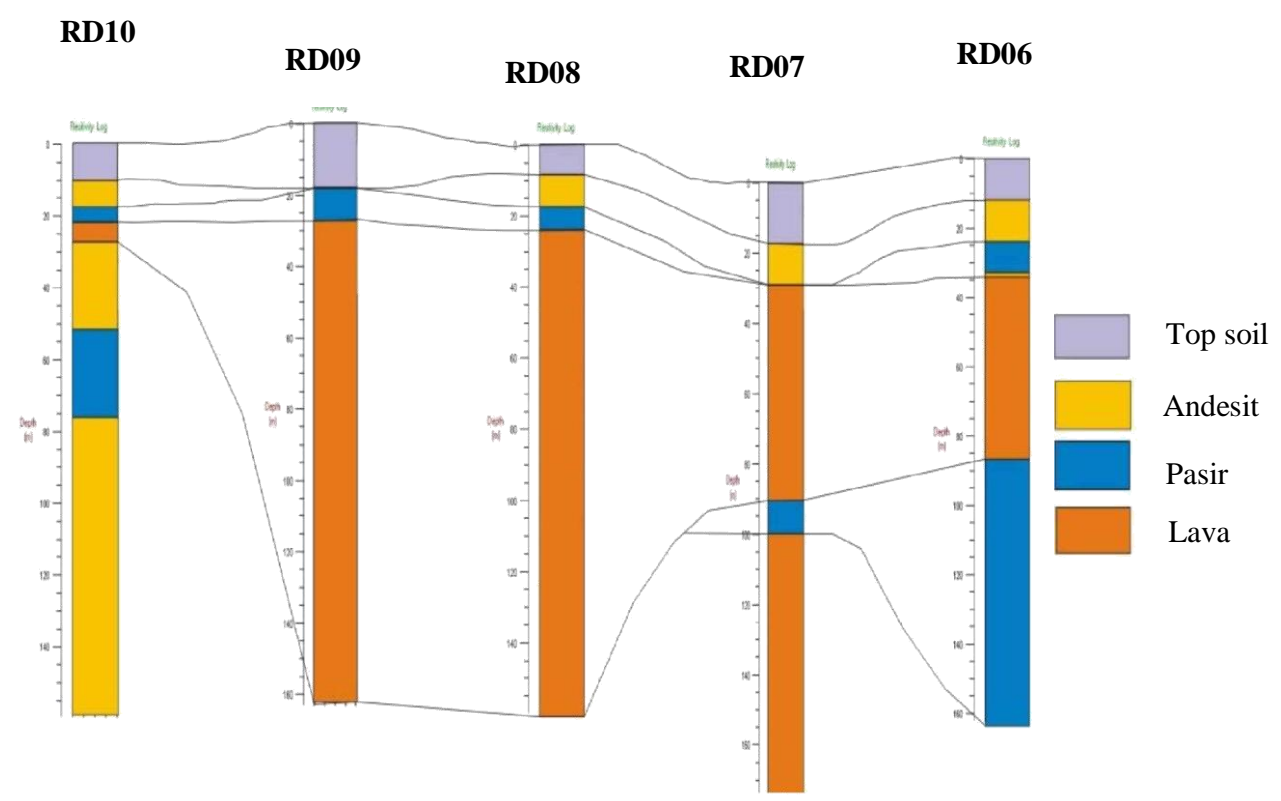

Gambar 2. Penampang 2D Titik RD10 sampai RD06

Kedua gambar di atas menunjukkan perbedaan kedalaman akuifer pada setiap titik. Kedalaman lapisan akuifer pada setiap titik, dapat dijabarkan sebagai berikut:

- Titik sounding RD01 pada kedalaman 25.4 meter dengan ketebalan 62.2 meter

- Titik RD02 pada kedalaman 16 meter dengan ketebalan 12.5 meter

- Titik RD03 pada kedalaman 35 meter dengan ketebalan 9 meter

- Titik RD04 tidak terdapat akuifer sebab tidak menunjukkan adannya lapisan dengan resistivitas rendah

- Titik RD05 pada kedalaman 32 meter dengan ketebalan 12 meter

- Titik RD06 pada kedalaman 20 meter dengan ketebalan 12.5 meter

- Titik RD07 pada kedalaman 90 meter dengan ketebalan 9 meter

- Titik RD08 pada kedalaman 17 meter dengan ketebalan 6 meter

- Titik RD09 pada kedalaman 18 meter dengan ketebalan 9 meter

- Titik RD10 pada kedalaman 17.6 meter dengan ketebalan 26 meter dan kedalaman 49.8 meter dengan ketebalan 26.2 meter.

\section{B. Pembahasan}

Berdasarkan potensi keberadaan lapisan akuifer di atas, seperti pada Gambar 1 dan Gambar 2 menunjukkan bahwa lapisan akuifer hampir menyebar ke segala arah dengan pola yang berbeda dan saling berkaitan antar titik pengukuran. Gambar 1 menunjukkan bahwa lapisan akuifer merupakan sebaran dari titik RD01, RD02 dan RD03. Titik RD04 memisahkan akuifer dengan dibatasi oleh lapisan batuan lava. Sehingga akuifer pada titik RD05 bukan akuifer yang terdapat pada 
titik RD01, RD02 dan RD03 melainkan lapisan akuifer tersendiri. Sedangkan pada Gambar 2 menunjukkan adanya sebaran akuifer dari titik RD10 sampai RD08. Akuifer pada titik RD06 bukan sebaran dari akuifer RD10 sampai RD08, hal ini dikarenakan adanya akuifer impermeabel pada titik RD07 berupa batuan lava.

Dilihat dari posisi masing-masing titik (lihat Gambar 1), akuifer pada titik RD01 sampai RD03 merupakan sebaran akuifer pada titik RD10 sampai RD08. Hal ini dikarenakan titik-titik tersebut terletak berdekatan dan sama-sama dipisahkan oleh lapisan pada titik RD04 dan RD07.

Berdasarkan hasil interpretasi, menunjukkan bahwa di bawah permukaan daerah penelitian terdapat potensi air tanah (akuifer). Potensi akuifer yang direkomendasikan untuk dilakukan eksplorasi air tanah berada pada titik RD01 pada kedalaman 25.4 meter dan ketebalan 62.2 meter serta titik RD10 yang mempunyai akuifer menggantung pada kedalaman 17.6 meter dengan ketebalan 4.2 meter dan kedalaman 49.8 meter dengan ketebalan 26.2 meter. Dasar rekomendasi eksplorasi ini diambil karena lapisan akuifer pada titik RD01 dan RD10 mempunyai ketebalan lebih dari 25 meter yang sehingga mempunyai volume air besar dibanding dengan titik yang lain.

\section{SIMPULAN DAN SARAN} bahwa:

Berdasarkan hasil penelitian yang telah dilakukan, maka dapat disimpulkan

1. Lapisan akuifer di daerah penelitian berada pada kedalaman 16 meter sampai 100.6 meter dengan ketebalan yang bervariasi, yaitu antara 4.2 meter sampai 62.2 meter dengan nilai resistivitas berkisar antara $6 \Omega \mathrm{m}$ sampai $106 \Omega \mathrm{m}$.

2. Terdapat dua sebaran akuifer yakni sebaran akuifer pertama terdapat pada titik pengukuran RD01, RD02, RD03, RD08, RD09, RD10 dan sebaran akuifer kedua pada titik pengukuran RD04, RD05, RD06, RD07.

3. Berdasarkan hasil tersebut, titik yang dianggap paling berpotensi untuk kegiatan eksplorasi pasir yakni di titik RD01 dengan perkiraan kedalaman $25.4 \mathrm{~m}$ ketebalan 62 m dan RD10 dengan perkiraan kedalaman 17.6 meter ketebalan 26 meter. Kedua titik tersebut mempunyai ketebalan lebih dari 25 meter sehingga diperkirakan mempunyai volume air yang besar dibanding dengan titik yang lain.

Hasil pengolahan dan interpretasi data geolistrik secara mutlak tidak dapat menggantikan data uji pengeboran, namun dapat memberikan informasi awal mengenai strategi untuk menentukan letak pengeboran. Maka dari itu, untuk mendapatkan hasil yang lebih baik diperlukan kalibrasi dengan sumur bor jika tersedia di sekitar lokasi penelitian.

\section{DAFTAR PUSTAKA}

[1] Prasetya, N. K. 2013. Potensi Pasir Pada Akuifer Rekahan Batuan Beku Berdasarkan Data Geolistrik dan Uji Pemompaan Di Ulubelu Geothermal Power Plant Project, Propinsi Lampung. Skripsi. Teknik Geologi Universitas Diponegoro, Semarang. 
[2] Abduh, M. 2012. Studi Kapasitas Debit Pasir Pada Akuifer Tertekan Di Kota Malang. Jurnal Teknik Pengairan. Vol 3 (1), hal. 71-80.

[3] Hanifa, D. 2016. Penentuan Lapisan Akuifer Pasir Dengan Metode Geolistrik Konfigurasi Schlumberger Di Desa Sungai Jati Kecamatan Mataraman Kabupaten Banjar Kalimantan Selatan. Jurnal Fisika FLUX.Vol 13 (1), hal. 30-39.

[4] Hakim, A.R, Hairunisa. 2018. Survey Geofisika Metode Geolistrik Resistivitas Untuk Menentukan Struktur Bawah Permukaan Desa Rada Kecamatan Bolo Kabupaten Bima. Prosiding National Conference on Mathematics, Sains and Education. Madura: 22 September 2018. Hal: 147-154

[5] Suryo, D. K, Supriyanto, Djayus. 2016. Studi Sebaran Potensi Pasir Di Kelurahan Tanah Merah Kecamatan Samarinda Utara Berdasarkan Resistivitas Batuan. Prosiding Seminar Sains dan Teknologi FMIPA Unmul. Maret 2016, Samarinda, Indonesia. Hal. 434-439.

[6] Sadjab, B. A, As'ari. 2012. Pemetaan Akuifer Pasir Di Sekitar Candi Prambanan Kabupaten Sleman Daerah Istimewa Yogyakarta Dengan Menggunakan Metode Geolistrik Tahanan Jenis. Jurnal MIPA Unsrat Online. 1 (1) : 37-44.

[7] Darsono. 2017. Identifikasi Potensi Akuifer Tertekan berdasarkan Data Resistivitas Batuan (Kasus : Kecamatan Sambirejo Kabupaten Sragen). Jurnal Fisika dan Aplikasinya. Vol 13 (1), hal. 34-38.

[8] Hakim, A.R, Hairunisa. 2017. Studi Struktur Bawah Permukaan Dengan Menggunakan Metode Geolistrik Resistivitas Konfigurasi Schlumberger (Studi kasus Stadion Universitas Brawijaya, Malang). Jurnal Pemikiran Penelitian Pendidikan dan Sains Wacana Didaktika UIM Madura: Vol 5 (1), hal. 56-64.

[9] Hakim, A.R, Hairunisa, Nurjumiati. 2017. Studi Akumulasi Rembesan Air Lindi Dengan Menggunakan Metode Geolistrik Resistivitas Konfigurasi Wenner Mapping (Studi kasus TPA Supit Urang, Malang). Jurnal Pendidikan Fisika dan Teknologi FKIP Universitas Mataram. Vol 3 (2), hal. 239-248.

[10] Zeffitni. 2008. Kajian Geometri Akuifer Berdasarkan Karakteristik Hidrokimia Pasir Untuk Penyediaan Air Bersih Di Kabupaten Donggala. Jurnal SMARTek. Vol 3 (1), hal. 57-64.

[11] Karunianto, A. J. 2013. Analisis Kedalaman Potensi Akuifer Pasir Dengan Pemodelan Distribusi Tahanan Jenis Secara Inversi 2-D Desa Kompas Raya, Nanga Pinoh, Melawi, Kalimantan Barat. Eksplorium. Vol 34 (1), hal. 11-22.

[12] Saranga, H. T, As'ari. 2016. Deteksi Pasir Menggunakan Metode Geolistrik Resistivitas Konfigurasi Wenner-Schlumberger di Masjid Kampus Universitas Sam Ratulangi dan Sekitarnya. Jurnal MIPA Unsrat Online.Vol 5 (2), hal. 70-75.

[13] Pratiknyo, P. 2008. Sistem Akuifer dan Cadangan Pasir Di Propinsi Sulawesi Selatan. Jurnal Ilmiah MTG. Vol 1 (1), hal. 1-10.

[14] Setiawan, T. 2016. Analisis Karakteristik Akuifer dan Zonasi Kuantitas Pasir di Dataran Kars Wonosari dan Sekitarnya, Kabupaten Gunungkidul, 
Arif Rahman Haķim dan Hairunisa/KONSTAN Volume 3, Nomor 2 Halaman 74-84

Provinsi Daerah Istimewa Yogyakarta. Jurnal Lingkungan dan Bencana Geologi. Vol 7 (3), hal. 145 -154. 